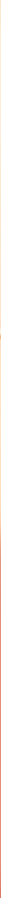

\title{
O PIBID/PEDAGOGIA E A GARANTIA DOS DIREITOS DE APRENDIZAGEM NAS DIVERSAS ÁREAS DO CONHECIMENTO
}

\section{RESUMO}

Este artigo apresenta alguns dos direitos de aprendizagem garantidos em diferentes áreas do conhecimento, durante as intervenções realizadas pelos projetos desenvolvidos no Programa Institucional de Bolsa de Iniciação à Docência (PIBID), subprojeto Pedagogia/ UFRN. Relata experiências vivenciadas nas turmas do $1^{\circ}$ ano A e B do Ensino Fundamental da Escola Municipal Professora Emília Ramos, localizada no bairro de Cidade Nova (Natal, RN), a partir dos projetos

A minha, a sua, a nossa cor e Repensando o lixo a partir da consciência ambiental. Os temas abordados nos projetos possibilitaram a garantia dos direitos de aprendizagem nas diversas áreas do conhecimento como o reconhecimento das semelhanças e diferenças existentes entre $\mathrm{o} / \mathrm{a}$ aluno/a criança e os colegas e o reconhecimento dos problemas ambientais existentes na comunidade e sua relação com a qualidade de vida e saúde. A metodologia utilizada considerou a utilização de vídeos, histórias literárias, 
produção de obras de arte com materiais recicláveis, jogos, brincadeiras, aula-passeio e atividades explorando os eixos estruturantes de ensino da Língua Portuguesa. Tudo isso com a finalidade de garantir os direitos de aprendizagem relacionados ao processo de alfabetização. Como resultados alcançados, destacam-se a aquisição de valores como o respeito às diferenças e ao meio ambiente, partindo do eu, sua relação com o outro e com o espaço em que vivemos.

Palavras-chave: Direitos de Aprendizagem. Alfabetização. PIBID.

\section{INTRODUÇÃO}

O presente artigo trata dos direitos de aprendizagem garantidos durante algumas intervenções realizadas no desenvolvimento de projetos na Escola Municipal Professora Emília Ramos, através do Programa Institucional de Bolsa de Iniciação à Docência (PIBID), subprojeto Pedagogia/UFRN. Os projetos Repensando o lixo a partir da consciência ambiental e $A$ minha, a sua, a nossa cor foram executados nas turmas do $1^{\circ}$ ano A e B, respectivamente. Neles, foram exploradas as diversas áreas do conhecimento de forma interdisciplinar: Língua Portuguesa, Geografia, História e Matemática, com foco no processo de Alfabetização dos alunos, garantindo alguns dos direitos de aprendizagem definidos pelo Pacto Nacional pela Alfabetização na Idade Certa (PNAIC), para cada uma dessas áreas, o que será relatado a partir de algumas experiências vivenciadas nas referidas turmas.

A pesquisa foi realizada através de consultas aos módulos elaborados para o curso de formação de professores organizado a partir do Pacto Nacional pela Alfabetização na Idade Certa (PNAIC), a fim de identificar quais direitos foram garantidos durante as intervenções realizadas pelo Programa Institucional de Bolsa de Iniciação à Docência (PIBID), visto que, desde 2013, o material tem direcionado a prática pedagógica dos professores do $1^{\circ}$ ao $3^{\circ}$ ano do Ensino Fundamental, na perspectiva de considerar os conhecimentos enquanto direitos que, portanto, devem ser garantidos. Tais direitos estão diretamente relacionados a eixos estruturantes, norteadores específicos da ação pedagógica em todas as áreas do conhecimento. Portanto, devem ser conhecidos e fazer parte dos objetivos a serem alcançados por qualquer intervenção pedagógica. Sendo assim, "para a realização de práticas pedagógicas estruturadas sob tais eixos, é relevante termos clareza dos direitos de aprendizagem especificamente relacionados a cada um deles, nos três primeiros anos do ensino fundamental" (BRASIL, 2012, p. 36).

Os direitos de aprendizagem passaram a permear toda ação pedagógica na escola e, os projetos desenvolvidos nela, devem estar em consonância com essas diretrizes que são preconizadas também no Plano Nacional da Educação (PNE), sendo uma das estratégias da meta 2: "a implantação dos direitos e objetivos de aprendizagem e desenvolvimento que configurarão a base nacional comum curricular do ensino fundamental" (BRASIL, 2014, p. 50).

Dessa forma, o conhecimento compartilhado na escola, possui diretrizes a serem seguidas, fruto de amplas discussões que consideram as necessidades da sociedade. Sendo assim, os projetos desenvolvidos nela devem ser direcionados de forma a contemplar em suas intervenções pedagógicas as orientações oficiais. 


\section{RECONHECENDO OS PROBLEMAS}

\section{AMBIENTAIS DA COMUNIDADE}

O projeto Repensando o lixo a partir de uma consciência ambiental surgiu da necessidade de se trabalhar o tema tendo em vista o contexto de epidemias vivenciado na Cidade do Natal, devido, dentre outros fatores, à falta de consciência ambiental, com o aumento de casos de Dengue, Zica e outras doenças, potencializadas pelo acúmulo de lixo nas ruas. Foi realizado na Escola Municipal Professora Emília Ramos e desenvolvido pelo PIBID Programa Institucional de Bolsa de Iniciação à Docência - com o foco voltado para o Ensino Fundamental - turma $1^{\circ}$ ano A. Também surgiu da necessidade de levar a criança a perceber o mundo a sua volta e de dar a devida importância para os cuidados com o meio ambiente e suas consequências, considerando o seu papel como agente transformador. Tem como objetivo ingressar no mundo letrado, construindo de forma gradativa o processo de alfabetização e letramento, trabalhar os conceitos referentes ao lixo e integrá-los à vida prática e cotidiana, desenvolvendo a cidadania e a conscientização junto a Educação Ambiental.

Durante a execução do projeto, foram feitas intervenções que exploraram os direitos de aprendizagem de forma a garanti-los durante o processo. Uma das intervenções realizadas de grande significação foi a "Aulapasseio pelas ruas ao redor da escola" que objetivou perceber o bairro observando a quantidade de lixo nas ruas e os animais que são atraídos por ele, assim como as doenças causadas e separar o lixo coletado de acordo com suas categorias.

Inicialmente, ainda em sala, houve o momento da roda de conversa numa retrospectiva acerca do tema estudado ao longo do projeto, na qual foi aberta uma discussão partindo do pensamento de cada criança ali compartilhado oralmente, levando em consideração a importância da interação entre a linguagem e o pensamento, proporcionando uma construção de diálogos sociais diante dos relatos trazidos por elas, como dizem Viera e Lopes:

\begin{abstract}
Mais que meio de comunicação ou expressão do pensamento, modos tradicionais como tem sido pensada, concebemos a linguagem como interação, como uma ação entre indivíduos, atividade social, histórica e, em função disso, como um dos elementos constitutivos do processo de humanização, da emergência do humano em cada indivíduo (VIEIRA; LOPES, 2012, p. 2).
\end{abstract}

Com esse momento foi contemplado um dos direitos de aprendizagem da oralidade - "Participar de interações orais em sala de aula, questionando, sugerindo, argumentando e respeitando os turnos de fala" (BRASIL, 2012). Posteriormente a conversa retrospectiva, houve a contação de história a partir do livro Bichionário (MACHADO, 2010) que é um modelo de dicionário de animais, o qual traz nomes, características e representações desses animais a partir de imagens. Os direitos abordados pertencentes ao eixo Leitura foram: "Ler textos não verbais, em diferentes suportes, e compreender textos lidos por outras pessoas de diferentes gêneros e com diferentes propósitos" (BRASIL, 2012). Já que a história possibilita a leitura não verbal e foi contada pelas professoras.

Logo após, houve a caminhada ao redor da escola, onde foi instruída a observação da quantidade de lixo nas ruas e as consequências trazidas, como, por exemplo, a diferença entre um canal de escoamento hidráulico limpo, no qual havia facilidade no escoamento de água, e outro sujo que havia uma obstrução por parte dos resíduos lá acumulados que poderiam causar doenças à população. Ressaltou-se, também, a importância da coleta desses resíduos, conscientizando os alunos/comunidade da relevância de dar a finalidade correta para o lixo, como traz o direito de aprendizagem 
pertencente à área de Geografia: "reconhecer os problemas ambientais existentes em sua comunidade e as ações básicas para a proteção do ambiente e sua relação com a qualidade de vida e saúde" (BRASIL, 2012).

Para Colesanti e Junqueira (2009, p. 3), ”O educador ambiental precisa transmitir informações que despertem em seus alunos interesse e vontade de conhecer mais o ambiente em que vivem para poder agir nele de forma crítica e com respeito" Durante o percurso, as crianças puderam presenciar a atitude de uma moradora de recolher o lixo da rua e de dar o destino correto a ele, deste modo, houve a possibilidade delas terem mais um direito de aprendizagem garantido, agora na área de Ciências, que foi: "identificar atitudes de cuidados com o ambiente como a limpeza da casa, rua, escola e o destino dos resíduos" (BRASIL, 2012). De volta à sala, houve o momento da separação de acordo com a classificação de reciclagem dos resíduos em suas respectivas latas - vidro, papel, plástico e metal -, pois entendemos a importância da reciclagem, como ressalta Colesanti e Junqueira:

A reciclagem tem fundamental importância para redução do acúmulo de lixo, pois grande parte do material que descartamos diariamente pode ser reciclado ou ainda reaproveitado. Ter conhecimento de sua importância é o primeiro passo, mas saber praticá-la é o maior desafio (COLESANTI; JUNQUEIRA, 2009, p. 9).

Em seguida, houve o momento para a construção e culminância da aula com a produção de um cartaz, a partir do que as crianças, com a ajuda da professora como escriba, fizeram um texto relatando o passeio ao redor da escola e escolheram um resíduo para colar junto ao cartaz com o seu respectivo nome e do objeto. Finalizando o último direito de aprendizagem garantido dessa intervenção que foi o da produção textual: "Produzir textos de diferentes gêneros, atendendo a diferentes finalidades, por meio da atividade de um escriba" (BRASIL, 2012).

Os alunos perceberam o bairro e suas problemáticas em relação ao lixo, identificaram a importância da coleta seletiva e a importância de colocar "o lixo no lixo", despertaram o interesse em cuidar e zelar por um ambiente limpo, jogando os resíduos no devido lugar, conseguiram distinguir as cores dos respectivos descartes, refletiram sobre as atitudes dos moradores do bairro e as consequências que o lixo causa à população (doenças, atração de insetos e animais indesejáveis, etc). Entenderam que "Todas as atividades humanas contribuem potencialmente, direta ou indiretamente, para as chamadas causas próximas das mudanças ambientais globais" (DIAS, 2002, p. 29) e que eles são capazes de promover essas mudanças.

\section{RECONHECENDO 0 EU E 0 OUTRO}

\section{A PARTIR DA LITERATURA INFANTIL}

O projeto $A$ minha, a sua, a nossa cor, desenvolvido na Escola Municipal Professora Emília Ramos situada na cidade de Natal/RN, em uma turma do $1^{\circ}$ ano do Ensino Fundamental, teve por objetivo discutir a relação étnico-racial, tendo em vista que a sociedade atual ainda é marcada por uma prática educativa excludente e europeizada, mesmo que de maneira sutil e mascarada. Tal projeto é viabilizado a partir do Programa Institucional de Bolsa de Iniciação à Docência (PIBID), subprojeto de Pedagogia da Universidade Federal do Rio Grande do Norte (UFRN).

Considerando que "Ensinar exige reconhecimento e assunção da identidade cultural" como diz Freire (2002, p. 23), o projeto tem por objetivo trabalhar com a diversidade étnico-cultural, na perspectiva de compreender a sociedade em sua complexidade de diferenças. Segundo o Ministério da Educação: 
A escola é um importante espaço de combate a preconceitos e discriminações. Os estudantes, ao conhecerem mais e melhor a organização social, política, econômica e cultural em que vivem, podem ampliar suas referências e compreender que o conceito de cidadania está estreitamente relacionado a um conjunto de direitos constitucionais estabelecidos e de valores sociais, tendo em vista a diversidade, a inclusão e o respeito às diferenças, especialmente em um país multicultural como o Brasil. (BRASIL, 2012, p. 37).

O projeto buscou contribuir ativamente no processo de alfabetização - aquisição de leitura e escrita - e no processo de letramento, tendo em vista que são temas bastante discutidos no âmbito educacional. Antigamente, a prática de alfabetizar era restrita à etapa em que o aluno apenas aprenderia a ler e a escrever, codificando e decodificando códigos, mas, com a incorporação dos conceitos sobre o letramento, esse período passou a ser de vital importância para a criança, pois não basta apenas saber ler e escrever. É necessário que haja uma compreensão da leitura e uma aplicabilidade da escrita para que os alunos passem a ter a formação de um sujeito plenamente alfabetizado e letrado, um cidadão capaz de agir socialmente.

No presente texto será enfatizada apenas uma das intervenções realizadas durante todo o projeto. Essa aula tinha como objetivos conceituais, procedimentais e atitudinais que os alunos pudessem relacionar o número a quantidade e interpretar questões sobre texto; expressar suas opiniões e preferências; apreciar a literatura com entusiasmo; respeitar as diferentes opiniões do outro; refletir sobre a diversidade das pessoas e experimentar momentos de leitura prazerosos;

A intervenção foi feita a partir do livro Bom dia todas as cores da autora Ruth Rocha embasada na concepção de Andaimagem (GRAVES; GRAVES, 1995), que divide a leitura do livro em três momentos: pré-leitura, leitura e pós-leitura e considera o aluno como participante ativo em todos esses processos.
No primeiro momento, foi feita uma roda de conversa e foram mostradas aos alunos as imagens da capa do livro, questionando-os sobre os elementos visuais presentes e levantando hipóteses sobre a história. Em seguida, foi feita a leitura com o livro pela professora e os alunos participaram ativamente comentando e fazendo inferências ao longo da história. $\mathrm{O}$ terceiro momento, da pós-leitura, foi organizado um jogo com os alunos, no qual as ilustrações do livro foram colocadas no chão em formato de um "caminho" no meio da sala. Os alunos, mediados pelas professoras, bolsistas do PIBID, teriam que puxar de uma caixa questões sobre a história e, após responder, teriam que colocar um número sorteado na ordem da ilustração. No quarto momento, foi feita a distribuição de bolas de encher coloridas, mas, antes, havíamos questionado sobre qual a cor predileta de cada um e, depois disso, distribuímos as bolas contrariando a preferência dos alunos.

É válido ressaltar que todas as questões, desde o momento da pré-leitura, foram feitas na perspectiva de que os alunos refletissem tanto na história em si, como, principalmente, nas suas relações com o outro.

Mediante a isso, ao longo das nossas intervenções em sala de aula, buscamos garantir com eficácia os Direitos de Aprendizagem aos alunos, visto que é de suma relevância para o fluir de um planejamento exitoso nas nossas práticas pedagógicas. $\mathrm{Na}$ realização dessa intervenção houve um resultado gratificante tanto para os alunos quanto para nós enquanto futuras professoras. Como registrado pelo Ministério da Educação:

\footnotetext{
A formação literária dos sujeitos está sustentada na concepção do papel da literatura na constituição social do indivíduo e da coletividade. Assim, a literatura contribui para desenvolver as capacidades interpretativas amplas dos leitores, as quais favorecem uma socialização mais rica, tendo em vista as estreitas relações entre os sentidos da vida, a constituição dos sujeitos e os textos literários. (BRASIL, 2012, p. 38).
} 
Em relação aos demais direitos de aprendizagem, baseando-se no documento do Pacto Nacional pela Alfabetização na Idade Certa (2012, p. 95), alcançamos na área de História o direito de "identificar e expressar (oralmente, graficamente e por escrito) as características (individuais e coletivas) comuns e particulares dos membros dos grupos de convívio dos quais participa (familiares, étnico-culturais, profissionais, escolares, de vizinhança, religiosos, recreativos, artísticos, esportivos, políticos, dentre outros), atualmente e no passado". Na área de Língua Portuguesa um dos direitos foi o de "Apreciar e compreender textos do universo literário (contos, fábulas, crônicas, poemas, dentre outros), levando-se em conta os fenômenos de fruição estética, de imaginação e de lirismo, assim como os múltiplos sentidos que o leitor pode produzir durante a leitura" (BRASIL, 2012, p. 32). Na área da Matemática, conseguimos alcançar dentre inúmeros direitos o de 'Estabelecer relações de semelhança e de ordem, utilizando critérios pessoais, diversificados e ampliados nas interações com os pares e com o professor para classificar, seriar e ordenar coleções, compreendendo melhor situações vivenciadas e tomar decisões" (BRASIL, 2012, p. 73).

Na culminância da aula, foram perceptíveis os frutos das atividades e, mais que isso, o alcance dos objetivos construídos no planejamento. O quarto momento foi de extrema relevância para a compreensão do respeito ao outro e do respeito a si mesmo, pois ao darmos balões diferentes das cores que eles tinham como preferidas, a reação foi de raiva, chateação e espanto, mas quando pedimos para que enchessem as bolas, houve uma pausa de reflexão de cada um deles quando colocamos a música Ser diferente é normal, cantada por Lenine, e solicitamos que eles brincassem com os balões. Foi gratificante ver que eles perceberam que independente de estarem com a cor predileta ou não em mãos, não deixaram de se divertir e de brincar por conta disso e, no fluir da música, eles trocaram os balões, riram uns dos outros e se reconheceram em suas particularidades e diferenças.

\section{CONSIDERAÇÕES FINAIS}

Como relatado nas experiências acima citadas, as contribuições do Programa Institucional de Bolsa de Iniciação à Docência (PIBID), têm ultrapassado seus objetivos de atuar na formação docente, proporcionando experiências de iniciação à docência a bolsistas em formação inicial. Mas o faz de forma sistematizada, planejada, de forma a considerar os objetivos da escola enquanto instituição responsável pela veiculação do conhecimento historicamente acumulado e necessário para formação de cidadãos capazes de participar ativamente da sociedade. Dessa forma, os projetos de intervenção do programa são realizados considerando os direitos de aprendizagem dos alunos, ou seja, os conhecimentos que devem ser a eles garantidos enquanto sujeitos de direitos, dentre eles, o da educação. 


\section{ABSTRACT}

This article presents some of the guaranteed learning rights in different areas of knowledge, during the interventions carried out by the projects developed in the Institutional Program of Initiation to Teaching Grant (PIBID), under Pedagogia/ UFRN project. It reports on the experiences of the first and second year classes A and B of the Elementary School of the Emília Ramos Municipal School, located in the neighborhood of Cidade Nova (Natal, RN), from the "My, Yours, Our Color" projects. "Rethinking the garbage from environmental awareness". The themes addressed in the projects made it possible to guarantee learning rights in the various areas of knowledge, such as the recognition of the similarities and differences

between the child and his / her colleagues and the recognition of environmental problems in the community and their relationship with the community. Quality of life and health. The methodology used included the use of videos, literary stories, production of works of art with recyclable materials, games, games, class-walk and activities exploring the structuring axes of Portuguese language teaching. All this in order to guarantee the learning rights related to the literacy process. As results achieved, we highlight the acquisition of values such as respect for differences and the environment, starting with the self, its relationship with the other and with the space in which we live.

Key words: Learning rights. Literacy. PIBID.

\section{RESUMEN}

Este artículo presenta algunos de los derechos garantizados de aprendizaje en diferentes áreas del conocimiento, durante las intervenciones de los proyectos desarrollados en el Programa Institucional de Beca de Iniciación a la Enseñanza (PIBID) sobprojeto Pedagogía / UFRN. Experiencias reportadas de la clase de $1^{\circ}$ año A y B de la Escuela Primaria de la Escuela Municipal Profesora Emília Ramos, ubicado en el barrio Ciudad Nueva (Natal, RN) del proyecto "Mi, tu, nuestro color" y "Repensando los residuos de la conciencia del medio ambiente." Los temas tratados en los proyectos han permitido garantizar los derechos de aprendizaje en diversas áreas del conocimiento, tales como el reconocimiento de las similitudes y diferencias entre el / a estudiante / niño

y sus colegas y el reconocimiento de los problemas ambientales en la comunidad y su relación con calidad de vida y la salud. La metodología considera el uso de videos, historias de la literatura, la producción de obras de arte con materiales reciclados, juegos, chistes, clase motrices y actividades que exploran los ejes estructurales de la enseñanza del portugués. Todo esto con el fin de garantizar los derechos relacionados con el aprendizaje de la lectoescritura. Como resultados obtenidos incluyen la adquisición de valores como el respeto a las diferencias y el medio ambiente, a partir de mí, su relación entre sí y con el espacio en el que vivimos.

Palabras clave: aprendizaje de los derechos. Alfabetización. PIBID. 


\section{REFERÊNCIAS}

BRASIL. Pacto nacional pela alfabetização na idade certa: currículo na alfabetização. Brasília: MEG, 2012.

BRASIL. Plano nacional de Educação 2014-2024. Disponível em: <http://www. observatoriodopne.org.br/uploads/reference/file/439/documento-referencia.pdf $>$. Acesso em: 4 set. 2017.

BRASIL. Pluralidade cultural. Disponível em: <http://portal.mec.gov.br/seb/arquivos/ pdf/pluralidade.pdf>. Acesso em: 4 set. 2017.

COLESANTI, Marlene T. M.; JUNQUEIRA, Berta A. Educação Ambiental: Formando a consciência desde a infância. In: IX ENCONTRO INTERNO E III SEMINÁRIO DE INICIAÇÃO CIENTÍFICA, 9., 2009, Uberlândia. Anais... Uberlândia: Universidade Federal de Uberlândia, 2009. p. 2-9.

DIAS, Genebaldo Freire. Pegada ecológica e sustentabilidade humana. São Paulo: Gaia, 2002.

GRAVES, M. F; GRAVES B. B. The scaffolding reading experience: a flexible framework for helping students get the most out of text. Reading, v. 29, n. 1, p. 29-34, abr. 1995. Disponível em: http://onlinelibrary.wiley.com/doi/10.1111/j.1467-9345.1995.tb00135.x/full

MACHADO, Nilson José. Bichionário. São Paulo: Escrituras, 2010.

ROCHA, Ruth. Bom dia todas as cores. São Paulo: Quinteto, 1998.

VIEIRA, Giane Bezerra; LOPES, Denise Maria de Carvalho. Linguagem, Alfabetização e Letramento: $\mathrm{O}$ trabalho pedagógico nos três primeiros anos do Ensino Fundamental e as especificidades da criança. Natal, RN : UFRN, 2012. [Módulo. Programa Continuum. Currículo e trabalho pedagógico nos três primeiros anos do Ensino Fundamental.] 